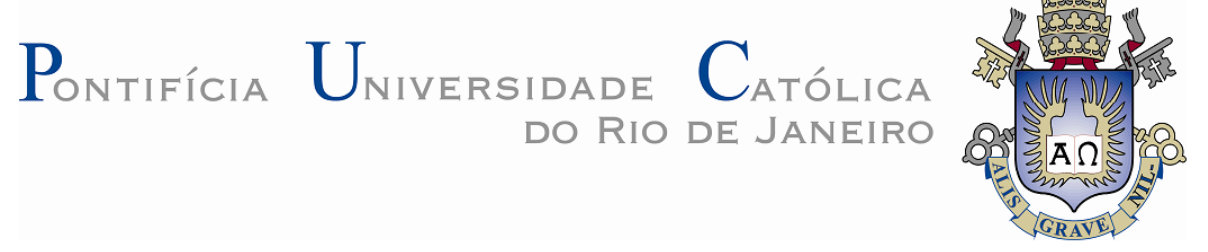

Gino Omar Calderón Vizcarra

Efeito da Granulometria no Comportamento Mecânico de Lastro Ferroviário

Tese de Doutorado

Tese apresentada como requisito parcial para obtenção do titulo de Doutor pelo Programa de Pós-Graduação em Engenharia Civil do Departamento de Engenharia Civil da PUC-Rio.

Orientadora: Profa. Michéle Dal Toé Casagrande Co-orientador: Prof. Buddhima Indraratna 


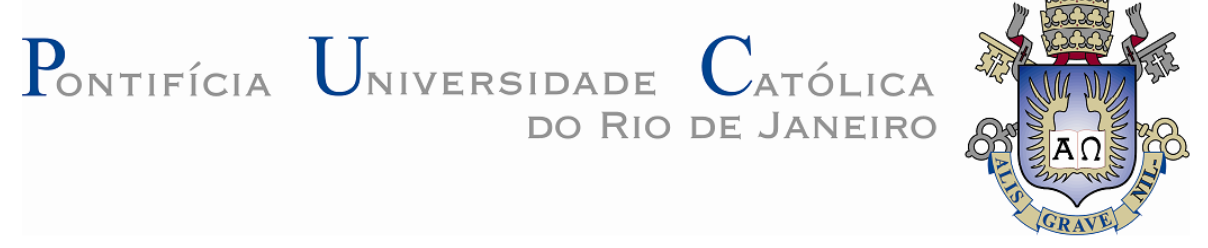

Gino Omar Calderón Vizcarra

\section{Efeito da Granulometria no Comportamento Mecânico de Lastro Ferroviário}

Tese apresentada como requisito parcial para obtenção do titulo de Doutor pelo Programa de Pós-Graduação em Engenharia Civil do Departamento de Engenharia Civil da PUC-Rio. Aprovada pela Comissão Examinadora abaixo assinada.

Profa. Michéle Dal Toé Casagrande

Orientadora

Departamento de Engenharia Civil - PUC-Rio

Profa . Laura Maria Goretti da Motta Universidade Federal do Rio de Janeiro

Prof. Antônio Carlos Rodrigues Guimarães Instituto Militar de Engenharia, IME/RJ

Dr. Luiz Francisco Muniz da Silva Muniz \& Spada Engenheiros Consultores S/C Ltda

Prof. Eurípedes do Amaral Vargas Jr. Departamento de Engenharia Civil - PUC-Rio

Profa. Raquel Quadros Velloso Departamento de Engenharia Civil - PUC-Rio

Prof. José Eugênio Leal Coordenador Setorial do Centro Técnico Científico - PUC-Rio 
Todos os direitos reservados. É proibida a reprodução total ou parcial do trabalho sem autorização da universidade, do autor e da orientadora.

\section{Gino Omar Calderón Vizcarra}

Graduou-se em Engenharia Civil pela Universidad Nacional Jorge Basadre Grohmann (Tacna - Perú). Em 2010 obteve o título de Mestre em Engenharia Civil no programa oferecido pelo Departamento de Engenharia Civil da PUC-Rio. Durante o período de doutorado, desenvolveu pesquisa na área de geotecnologia ferroviária. Atualmente trabalha na firma Muniz \& Spada engenheiros consultores no Rio de Janeiro.

Ficha Catalográfica

Calderón Vizcarra, Gino Omar

Efeito da granulometria no comportamento mecânico de lastro ferroviário / Gino Omar Calderón Vizcarra ; orientadora: Michéle Dal Toé Casagrande ; co-orientador: Buddhima Indraratna. - 2015.

130 f. : il. (color.) ; $30 \mathrm{~cm}$

Tese (doutorado)-Pontifícia Universidade Católica do Rio de Janeiro, Departamento de Engenharia Civil, 2015. Inclui bibliografia

1. Engenharia civil - Teses. 2. Lastro ferroviário. 3. Granulometria. 4. Ensaio triaxial. 5. Métodos dos elementos discretos. I. Casagrande, Michéle Dal Toé. II. Indraratna, Buddhima. III. Pontifícia Universidade Católica do Rio de Janeiro. Departamento de Engenharia Civil. VI. Título. 


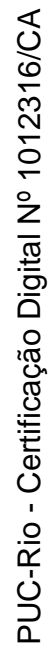

Ao meu pai,

Rosendo Calderón Alanoca. 


\section{Agradecimentos}

Passou algum tempo desde que comecei este empreendimento, além de uma pesquisa acadêmica, é fruto de trabalho intenso, perseverança, emoções e sentimentos.

Ao longo desta caminhada, contei com o apoio de muitas pessoas, sirva estas poucas palavras para tentar agradecer a maioria delas, desculpem àquelas que não consigo lembrar neste momento.

Primeiramente agradeço à minha família, especialmente ao meu pai, Rosendo, quem me formou para poder afrontar todas as dificuldades que a vida coloca no caminho; à minha mãe Rosa, pelo amor e carinho; à minha avó Carmen, aos meus tios, irmãos e primos, por sempre estarem pendentes de mim e ser aquela força necessária para continuar neste caminho.

À minha orientadora Prof ${ }^{a}$. Michéle Dal Toé Casagrande, quem sempre apostou por mim, me brindando total apoio para conseguir os meus objetivos.

Ao prof. Buddhima Indraratna, por ter me aceito como pesquisador visitante na Universidade de Wollongong, o qual tem sido uma experiência marcante na minha vida.

Ao Dr. Sanjay Nimbalkar, pelas valiosas contribuições na minha pesquisa na área ferroviária e apoio constante desde que cheguei a Wollongong até hoje.

Ao meu amigo Dr. Mehdi Biabani, por ter me ajudado na realização dos ensaios na Universidade de Wollongong, e por sua sincera amizade, obrigado por me mostrar que a generosidade independe da nacionalidade, crença ou língua.

À Prof ${ }^{\mathrm{a}}$. Ana Ribeiro Heitor, por sua gentil ajuda na minha chegada à Wollongong, também pelos cafés, companhia e conselhos.

Aos funcionários do Laboratório de Geotecnia da UOW: Ian Bridge, Rick McLean, Col Devenish, Cameron Neilson, Nando Ecribano, Wayne Ireland e especialmente ao Alan Grant pelo apoio durante a realização dos ensaios.

Aos colegas da UOW: Qideng Sun, Dennis Alazhiga, Hooman Ghojavand, Firman Siahaan, Arash Moslemi, Soledad Mashiri.

Aos meus vizinhos de "Gundi" na Austrália em especial aos meus "housemates": Nima Mirsepassi, Fred Raof, Nadeera Ranabahu, Miho Sugiura, Afsaneh Khansari, Vi Nguyen e Nelson, por ter me acolhido em "Unit 6", também aos meus amigos: Alex Arce, Ernesto Lozano, Katerina, Fariba e Silvana. 
À firma Muniz \& Spada engenheiros consultores, especialmente aos meus mestres: Dr. Luis Francisco Muniz da Silva e Dr. Jorge Goudene Spada, por ter me incentivado a fazer pesquisa nesta área, e brindado valioso apoio. Muito obrigado pelos ensinamentos.

Também agradeço aos colegas com os quais compartilhei o trabalho diário: Candice, Mariângela, Marcelo, Janaina, Jefferson, Marcio, Welson, Rosemeri, Flavio, Claudio, Frederico, Silvana, Raissa, Mari, Matilde, Antonia, Carlos e Rulian.

Aos meus amigos no Rio de Janeiro, especialmente à Juliana Meza, Nilthson Noreña, Bruno Carvalho, Carlos Paredes e Antônio Nunes.

Aos integrantes do time olímpico: Luis Fernando, Elvis, Eliot e Julio pelas inúmeras histórias vivenciadas.

À firma Intertechne, por ter me acolhido durante o último período da tese, especialmente ao José Henrique Pereira, Marcelo Miqueletto, Pedro Thá.

Ao meu amigo João Guedes Pinto, também ao Otto, Marcel, Cesar e Joaquin pelas boas risadas no espanhol, obrigado por fazerem sentir em casa, o período que estive em Curitiba.

Ao Laboratório de Engenharia de Transportes da USP, à Prof ${ }^{a}$. Liedi Bernucci, Robson Costa e Antonio Merheb por ter compartilhado gentilmente as suas experiências no ensaio triaxial cíclico.

Aos meus amigos da Universidad Nacional de Tacna, no Perú (Código 96): por sempre torcerem por mim.

Aos integrantes da banca examinadora que contribuíram para a revisão com sugestões para a melhoria do trabalho.

A todos os amigos e amigas de mestrado e doutorado que compartilharam das várias etapas transcorridas durante o doutoramento.

Ao CNPq, a CAPES e à PUC-Rio, pelos auxílios concedidos, sem os quais este trabalho não poderia ter sido realizado.

A todos os funcionários da PUC que sempre deram o apoio necessário para o bom andamento das atividades, em especial a Rita de Cássia.

E por último e não menos importante, à Jucicléia Florencio, pelo amor, paciência, felicidade e paz destes últimos tempos. 


\section{Resumo}

Vizcarra, Gino Omar Calderón; Casagrande, Michéle Dal Toé; Indraratna, Buddhima. Efeito da Granulometria no Comportamento Mecânico do Lastro Ferroviário. Rio de Janeiro, 2015. 130 p. Tese de Doutorado. Departamento de Engenharia Civil, Pontifícia Universidade Católica do Rio de Janeiro.

O efeito da granulometria no comportamento mecânico do lastro tem sido estudado por vários pesquisadores. A revisão destes estudos indicou que uma granulometria mais uniforme que as atualmente usadas pela indústria ferroviária diminuiria a deformação permanente e a degradação do lastro ferroviário. Neste estudo, foi utilizado o equipamento prismoidal triaxial cíclico, projetado e construído na Universidade de Wollongong - Austrália. O deslocamento lateral do lastro ferroviário no campo não está restrito, devido a insuficiente tensão lateral (tensão confinante); por isso a câmera prismoidal triaxial com lados não restritos é uma instalação ideal para a modelagem física das deformações do lastro. Duas granulometrias de lastro foram testadas, sob tensão vertical cíclica máxima de 450 $\mathrm{kPa}$. Uma delas estava de acordo com a granulometria recomendada por Indraratna et al. (2004), para revisão da Norma Australiana AS 2758.7 (1996) e a outra foi preparada em concordância com a norma Brasileira, NBR 5564. Os resultados mostram que a granulometria tem grande influência na deformação permanente e na quebra de lastro ferroviário. Também se apresenta a modelagem de um ensaio de compressão sobre lastro ferroviário utilizando o método dos elementos discretos. Utilizaram-se propriedades típicas de lastro ferroviário tais como peso específico, granulometria, índice de vazios e espessura das camadas. O ensaio virtual compreende a aplicação de uma carga vertical monotônica mediante uma peça de dimensões similares a um dormente, sobre partículas que simulam o lastro colocado numa caixa de dimensões 600 × 800 x $800 \mathrm{~mm}$. São observadas as tensões e velocidades desenvolvidas nas partículas, características difíceis de serem observadas nos ensaios convencionais reais.

\section{Palavras-chave}

Lastro ferroviário; granulometria; ensaio triaxial; método dos elementos discretos. 


\section{Abstract}

Vizcarra, Gino Omar Calderón; Casagrande, Michéle Dal Toé (Advisor); Indraratna, Buddhima (Co-advisor). Effect of Particle-size-distribution on Mechanical Behavior of Railway Ballast. Rio de Janeiro, 2015. 130 p. DSc. Thesis - Departamento de Engenharia Civil, Pontifícia Universidade Católica do Rio de Janeiro.

The effect of the particle-size-distribution on mechanical behaviour of ballast has been studied by several researchers in the past. The review of these past studies indicated that more uniform gradation than actually used by the railway industry would decrease permanent deformation and degradation of railroad ballast. In this study, the prismoidal cyclic triaxial apparatus designed and built at the University of Wollongong was used. The lateral displacement of railroad ballast in the field is not restricted in the absence of sufficient lateral stress (confining pressure); hence the prismoidal triaxial chamber with unrestrained sides provides an ideal facility for physical modeling of the deformations of ballast. Two different particle size distributions of ballast were tested under cyclic vertical maximum stress of about $450 \mathrm{kPa}$. One of them was according to PSD recommended by Indraratna et al. (2004) as an improvement to Australian Standard AS 2758.7 (1996) and the other one was prepared in accordance with Brazilian standard NBR 5564. The results showed that gradation had major influence on the permanent deformation and breakage of railroad ballast. Also, it is presented a compression test modelling on railway ballast using the discrete element method. Typical railways ballast properties, such as specific weight, particle-size-distribution, void ratio, layers thickness were used. The virtual test comprises monotonic vertical loading through a piece with similar dimensions to sleeper on particles that simulates ballast inside a $600 \times 800 \times 800$ $\mathrm{mm}$ box. Stresses and velocities developed in particles are observed, which are difficult sighting characteristics in real conventional tests.

\section{Keywords} method.

Railway ballast; particle-size-distribution; triaxial test; discrete element 


\section{Sumário}

1 Introdução

1.1 Relevância e justificativa da pesquisa 22

1.2 Objetivos 24

1.3 Organização da Tese 24

2 Revisão Bibliográfica $\quad 25$

2.1 Características da partícula 25

2.1.1 Tamanho da partícula $\quad 25$

2.1.2 Angularidade da Partícula 28

2.1.3 Forma da partícula 29

2.1.4 Textura da superfície 30

2.1.5 Resistência da rocha mãe 31

2.1.4.1 Identificação petrográfica de tipos de rocha 31

2.1.4.2 Análise petrográfica de lâmina delgada 32

2.1.4.3 Difração de raios- $X$

2.1.5 Resistência ao esmagamento da partícula 33

2.2 Características dos agregados 34

2.2.1 Granulometria 34

2.2.1.1 Especificação Brasileira 38

2.2.1.2 Especificação Australiana 40

2.2.1.3 Especificação dos Estados Unidos 43

2.2.1.4 Especificação Européia 46

2.2.1.5 Especificação Russa $\quad 47$

2.2.2 Índice de vazios $\quad 48$

2.3 Características do carregamento. $\quad 49$

2.3.1 Tensão confinante 49

2.3.2 Historia de tensões $\quad 51$

2.3.3 Estado de tensões atual $\quad 54$

2.3.4 Número de ciclos de carga $\quad 55$

2.4 Degradação da partícula $\quad 59$ 
3 Ensaio Triaxial Cíclico 63

3.1 Introdução 63

3.2 Equipamento prismoidal triaxial cíclico 64

3.2.1 Célula triaxial prismoidal 66

$\begin{array}{ll}3.2 .2 \text { Unidade de carregamento axial } & 67\end{array}$

$\begin{array}{ll}\text { 3.2.3 Sistema de controle de pressão confinante } & 67\end{array}$

3.2.4 Dispositivos de monitoramento de deslocamento horizontais e verticais $\quad 70$

$\begin{array}{ll}3.3 \text { Materiais } & 71\end{array}$

3.3.1 Sublastro $\quad 71$

3.3.2 Lastro $\quad 74$

3.4 Procedimentos do Ensaio $\quad 80$

3.4.1 Preparação de amostras $\quad 80$

3.4.2 Carregamento 90

3.5 Programa experimental 91

3.6 Resultados experimentais 94

3.6.1 Características de recalque 94

3.6.2 Características da deformabilidade 96

3.6.3 Módulo resiliente $\quad 97$

3.6.4 Quebra de partículas 98

4 Simulação Numérica 102

4.1 O Método dos Elementos Discretos 102

4.2 Modelagens do Ensaio 105

4.2.1 Modelo 105

4.2.2 Descrição de Partículas 106

4.2.3 Passo de tempo 109

4.2.4 Geração de partículas 111

4.2.5 Carregamento 112

4.3 Resultados 113

4.3.1 Evolução da deformação 113

4.3.2 Tendência de movimento do lastro 118

4.3.3 Sobreposição de partículas 119 
5 Considerações finais 121

5.1 Conclusões 121

5.1.1 Ensaio triaxial cíclico 121

5.1.2 Simulação numérica 122

$\begin{array}{ll}5.2 \text { Sugestões para pesquisas futuras } & 123\end{array}$

6 Referências Bibliográficas 124 


\section{Lista de Figuras}

Figura 1.1. Expansão da malha ferroviária brasileira (PAC 2).

Figura 2.1. Efeito do tamanho de grão no ângulo de atrito (Marachi et al., 1972).

Figura 2.2. Efeito do tamanho de grão no Modulo Resiliente do Lastro (Janardhanam e Desai, 1983).

Figura 2.3. Influencia da forma da partícula na resistência (Holz e Gibbs, 1956).

Figura 2.4. Efeito da forma da partícula no ângulo de atrito (Vallerga et al.).

Figura 2.5. Diagrama de um microscópio petrografico padrão e visualização ampliada da amostra de rocha (Idaho State University, 2015).

Figura 2.6. Diagrama simplificado do difratômetro de raios-x.

Figura 2.7.(a) Graduação de partículas, e seus efeitos em (b) ângulo de atrito, (c) densidade, (modulo de cisalhamento) e (e) permeabilidade. Thom e Brown (1988)

Figura 2.8. Efeitos da graduação nas deformações verticais do lastro sob carregamento cíclico (Raymond e Diyaljee, 1979).

Figura 2.9. Distribuições granulométricas - ABNT NBR 5564:2012 40

Figura 2.10. Distribuições granulométricas - AS 2758.7.

Figura 2.11. Distribuições granulométricas - RIC e Queensland Rail (Indraratna et al, 2011).

Figura 2.12 - Distribuições granulométricas- AREMA (2009) 45

Figura 2.13 - Distribuições granulométricas - EN 13450 (2003) 47

Figura 2.14 - Distribuição granulométrica para ferrovias russas. $\quad 48$

Figura 2.15. Envoltória de resistência não linear a baixas pressões confinantes (Charles e Watts, 1980).

Figura 2.16. Influencia da pressão confinante no ângulo de atrito (Indraratna et al, 1998). 
Figura 2.17. Efeitos da historia de tensões na deformação do lastro sob carregamento cíclico. (a) Tensao desviadora até $210 \mathrm{kPa}$, (b) Tensao cíclica acima de 210 kPa (Diyaljee, 1987)

Figura 2.18. Efeitos do estado de tensões nas deformações plásticas (Poorooshasb et al, 1966)

Figura 2.19. Recalque de via após socaria, (a) em escala plana, (b) em escala semi-log (Shenton, 1975)

Figura 2.20. Efeitos de ciclos de carga nas deformações axial e volumétrica (Raymond et al, 1975)

Figura 2.21. Recalque de via em diferentes partes do mundo (Shenton, 1975).

Figura 2.22. Recalque de lastro sob carregamento cíclico (Jeffs e Marich, 1987).

Figura 2.23. Recalque de lastro sob carregamento cíclico (Ionescu et al, 1998).

Figura 2.24. Determinação do Índice de quebra de lastro (BBI).

Figura 2.25. Efeito da quebra de partículas na razão de tensões principais na ruptura (Marsal, 1967).

Figura 2.26. Efeito da taxa de quebra de partículas na razão de tensões principais na ruptura (Miura e O-hara, 1979)

Figura 2.31. Influência da quebra de partículas na razão de tensões principais e o ângulo de atrito (Indraratna et al., 1998)

Figura 3.1. Equipamento triaxial prismoidal cíclico da Universidade de Wollongong na Austrália.

Figura 3.2. Ilustração esquemática em planta da câmera triaxial cíclica (dimensões em mm)

Figura 3.3. Ilustração esquemática na seção Y-Y da câmera triaxial cíclica (dimensões em $\mathrm{mm}$ )

Figura 3.4. Ilustração esquemática na seção $X-X$ da câmera triaxial cíclica (dimensões em $\mathrm{mm}$ ) 66

Figura 3.5. Unidade de carregamento axial do equipamento triaxial 67

Figura 3.6. Vista lateral do equipamento 68

Figura 3.7. Detalhe da unidade de carregamento lateral 
Figura 3.8. Detalhe da unidade de carregamento lateral

Figura 3.9. Detalhe da unidade de carregamento lateral

Figura 3.10. Detalhe do computador de aquisição de dados da instrumentação

Figura 3.11. Tela de controle do atuador de carga 71

Figura 3.12. Granulometria do sublastro $\quad 72$

Figura 3.13. Sublastro $\quad 73$

Figura 3.14. Analise mineralógica qualitativa por difratometria de raios $\mathrm{x} \quad 75$

Figura 3.15. Diagrama QAPF de um latito típico 76

Figura 3.16. Gradação A

Figura 3.17. Gradação B $\quad 78$

Figura 3.18. Granulometria e coeficiente de uniformidade dos dois lastros utilizados nesta pesquisa. $\quad 79$

Figura 3.19. Peneiramento do lastro nesta pesquisa

Figura 3.20. Diferentes tamanhos de partícula para obter uma granulometria.

Figura 3.21. Câmera triaxial vazia. $\quad 82$

Figura 3.22. Compactação de camada de sublastro. 83

Figura 3.23. Arranjo da instrumentação na interface sublastro-lastro. 83

Figura 3.24. Vista superior do topo do lastro de suporte antes de colocar o dormente. $\quad 84$

Figura 3.25. Colocação do dormente 84

Figura 3.26. Enchimento do lastro do ombro 85

Figura 3.27. Vista lateral $\quad 85$

Figura 3.28. Topo da câmera triaxial mostrando dormente e trilho $\quad 86$

Figura 3.29. Colocação de LVDTs no dormente 86

Figura 3.30. Medição dos deslocamentos verticais.

Figura 3.31. Fim do ensaio $\quad 87$

Figura 3.32. Quebra de partículas 88

Figura 3.33. Retiro do material ensaiado 88

Figura 3.34. Material fino que provem do lastro ao final do ensaio. $\quad 89$

Figura 3.35. Detalhe do material fino 89 
Figura 3.36. Quantidade do material fino

Figura 3.37. Detalhe do carregamento cíclico, $\mathrm{f}=15 \mathrm{~Hz}$ (carga do atuador)

Figura 3.38. Detalhe do carregamento cíclico, $f=15 \mathrm{~Hz}$ (tensão no contato dormente-lastro)

Figura 3.39. Detalhe do carregamento cíclico, $f=25 \mathrm{~Hz}$ (carga do atuador)

Figura 3.40. Detalhe do carregamento cíclico, $\mathrm{f}=25 \mathrm{~Hz}$ (tensão no contato dormente-lastro)

Figura 3.41. Comparação do deslocamento vertical no contato lastro-face inferior do dormente para ambas as granulometrias na frequência $15 \mathrm{~Hz}$.

Figura 3.42. Comparação do deslocamento vertical no contato lastro-face inferior do dormente para ambas as granulometrias na frequência $25 \mathrm{~Hz}$.

Figura 3.43. Comparação do deslocamento vertical contato lastroface inferior do dormente para a granulometria $\mathrm{A}$ e diferentes frequências de carregamento cíclico.

Figura 3.44. Comparação do deslocamento vertical contato lastroface inferior do dormente para a granulometria $B$ e diferentes frequências de carregamento cíclico.

Figura 3.45. Comparação da deformação vertical da camada do lastro para ambas as granulometrias e diferentes frequências de carregamento cíclico.

Figura 3.46. Comparação da deformação volumétrica da camada do lastro para ambas as granulometrias e diferentes frequências de carregamento cíclico.

Figura 3.47. Comparação da deformação cisalhante da camada do lastro para ambas as granulometrias e diferentes frequências de carregamento cíclico.

Figura 3.48. Variação do Modulo Resiliente com o numero de ciclos. 
Figura 3.49. Comparação da mudança no tamanho de partícula do lastro para ambas as granulometrias sob carregamento cíclico.

Figura 3.50. Comparação da mudança no tamanho de partícula do lastro para a granulometria $\mathrm{A}$ e diferentes frequências de carregamento cíclico.

Figura 3.51. Avaliação do índice de quebra de lastro para a graduação A

Figura 3.52. Avaliação do índice de quebra de lastro para a graduação B

Figura 4.1. Diagrama do modelo de contato Hertz-Mindlin (adaptado de Roufail, 2011).

Figura 4.2. Ilustração da câmera triaxial.

Figura 4.3. Granulometria e coeficiente de uniformidade dos lastros modelados numericamente.

Figura 4.4. Numero de partículas vs. Diâmetro para cada granulometria dos lastros modelados numericamente.

Figura 4.5. Linha do tempo do ensaio.

Figura 4.6. Criação de partículas. (a) sub-lastro, (b) lastro.

Figura 4.7. Força vertical no contato dormente - lastro para a granulometria B aos 4 segundos.

Figura 4.8. Força vertical total no contato dormente/lastro comparação entre granulometrias A e B na modelagem numérica desta pesquisa..

Figura 4.9. Força vertical total no contato dormente/lastro comparação entre granulometrias C, D e E na modelagem numérica desta pesquisa.

Figura 4.10. Força vertical total no contato dormente/lastro comparação entre diferentes frequências de carregamento para a granulometria $A$, na modelagem numérica desta pesquisa.

Figura 4.11. Força de compressão em partículas aos 4 segundos, para a granulometria $B$, na modelagem numérica desta pesquisa.

Figura 4.12. Força de compressão media na partícula vs. Diâmetro das partículas (comparação entre granulometrias), na modelagem 
numérica desta pesquisa.

Figura 4.13. Numero de contatos (comparação entre granulometrias), na modelagem numérica desta pesquisa.

Figura 4.14. Vetores de velocidade do lastro na seção média da caixa durante o carregamento (Granulometria B) na modelagem numérica desta pesquisa.

Figura 4.15. Posição no eixo X vs. Sobreposição normal das partículas de diâmetro $63 \mathrm{~mm}$ (Granulometria B), na modelagem numérica desta pesquisa.

Figura 4.16. Posição no eixo X vs. Sobreposição normal das partículas de diâmetro $15 \mathrm{~mm}$ (Granulometria B), na modelagem numérica desta pesquisa. 


\section{Lista de Tabelas}

Tabela 2.1. Classificação do lastro quanto à contaminação (Selig e Waters, 1994)

Tabela 2.2. Características do lastro ferroviário segundo a norma brasileira NBR 5564:2012.

Tabela 2.3. Distribuição granulométrica do lastro-padrão segundo a norma brasileira NBR 5564:2012.

Tabela 2.4. Requerimentos de granulometria pela norma Australiana AS2758.7 (Standards Australia, 1996)

Tabela 2.5. Requerimentos de granulometria pela Queensland Rail e RIC (Apud Indraratna et al. 2011)

Tabela 2.6. Requerimentos de granulometria da AREMA (Graduações 24, 25 e 3)

Tabela 2.7. Requerimentos de granulometria da AREMA (Graduações 4A, 4, 5 e 57)

Tabela 2.8. Requerimentos de granulometria pela norma EM 13450 (2003)

Tabela 2.9. Requerimentos de granulometria pela norma russa.

Tabela 3.1. Locais onde foram realizados ensaios triaxiais de grande escala em estudos de lastro (Apud Merheb et al., 2014).

Tabela 3.2. Faixa granulométrica do sublastro recomendado pelo Public Transport Victoria (1997) e a granulometria do sublastro utilizado.

Tabela 3.3. Análise química quantitativa total por espectrometria de fluorescência de raios-X.

Tabela 3.4. Composição mineralógica, identificados por comparação com os padrões do ICDD (International Centre for Diffraction Data).

Tabela 3.5. Granulometria de lastro recomendada por Indraratna et al (2004)

Tabela 3.6. Granulometria de lastro segundo a norma brasileira (NBR 5564:2012) 
Tabela 3.7. Comparação das granulometrias dos materiais utilizados nesta pesquisa.

Tabela 3.8. Resumo dos ensaios realizados.

Tabela 4.1. Parâmetros da simulação numérica adotados para esta pesquisa

Tabela 4.2. Granulometria A

Tabela 4.3. Granulometria B

Tabela 4.4. Granulometria C

108

Tabela 4.5. Granulometria D 108

Tabela 4.6. Granulometria E 108 


\section{Lista de Abreviaturas}

$\begin{array}{ll}\text { ABNT } & =\text { Associação Brasileira de Normas Técnicas } \\ \text { NBR } & =\text { Norma Brasileira } \\ \text { CBR } & =\text { Califórnia Bearing Ratio } \\ \mathrm{CH} & =\text { Argila Inorgânica de Alta Plasticidade }\end{array}$




\section{Lista de Símbolos}

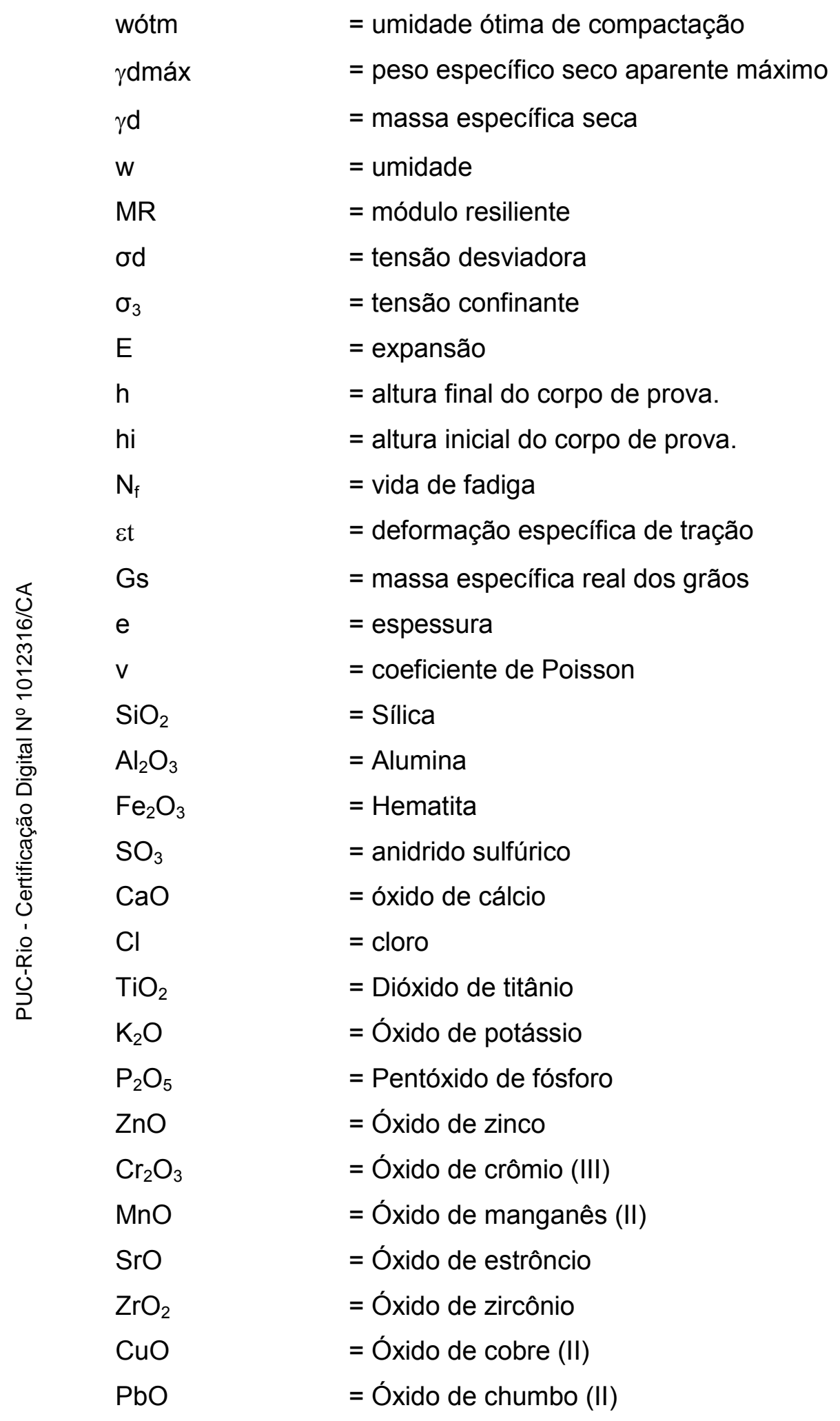

